\title{
1 Real-time Detection and Tandem Mass Spectrometry of Secondary 2 Organic Aerosols with a Quadrupole Ion Trap
}

\author{
G. Asher Newsome ${ }^{\mathrm{a}}$, Elias P. Rosen ${ }^{\mathrm{a}, \mathrm{b}}$, Richard M. Kamens ${ }^{\mathrm{b}}$, Gary L. Glish ${ }^{\mathrm{a} *}$
}

a'Department of Chemistry, University of North Carolina at Chapel Hill, Chapel Hill, NC 27599-3290

${ }^{b}$ Department of Environmental Sciences and Engineering, University of North Carolina at Chapel Hill, Chapel Hill, NC 27599$7 \quad 3290$

An aerosol quadrupole ion trap mass spectrometer is reported that is sensitive, has unique capabilities to perform chemical ionization, is operated in real-time, and is able to perform tandem mass spectrometry. The instrument samples particles with an aerodynamic lens and volatilizes them within the heated ion trap electrode assembly. Analyte molecules are ionized within the ion trap by proton transfer from reagent ions, and resultant fragmentation is reduced compared to vacuum UV photoionization. Particle concentrations can be detected linearly over two orders of magnitude and as low as $5 \mu \mathrm{g} / \mathrm{m}^{3}$. To demonstrate the real-time analysis capability of the instrument, secondary organic aerosol particles were produced by reaction of $100 \mathrm{ppb} \alpha$ pinene and $200 \mathrm{ppb}$ ozone in an aerosol bag and observed in real-time to monitor the progress of the reaction. Pinic acid and pinonic acid are two of the many components of the secondary aerosol mixture that form and gradually decrease in concentration. Individual concentrations are calculated using pinic acid as an internal standard and vary from 4-36 ppb. The identities of analyte ions from both compounds are confirmed by tandem mass spectrometry in real-time.

Mass spectrometry is necessary to differentiate aerosol species in complex mixtures and to measure component compound mass concentrations. Many mass spectrometers have been designed to detect aerosol particles with different combinations of volatilization techniques, ionization sources, and mass analyzers. ${ }^{1,2}$ Of these, flash thermal volatilization and electron ionization (EI) with a time-of-flight mass spectrometer (TOFMS) is common and has been commercialized. EI causes extensive fragmentation that makes it difficult to identify compounds in complex mixtures. A critical need remains for more specific characterization. Alternative ionization methods have been used that cause less fragmentation for some compounds. UV laser desorption and ionization is very sensitive for some particles but also tends to cause high levels of fragmentation of organics. ${ }^{3,4}$ Vacuum UV ionization has been shown to further reduce fragmentation and has been applied to particles vaporized on a heated surface ${ }^{5}$ and by IR laser irradiation. ${ }^{6,7}$ Chemical ionization causes the least fragmentation and has been used with particle collection/flash thermal vaporization on the order of minutes. ${ }^{8,9}$ Chemical ionization has also been used for real-time analysis ${ }^{10,11}$, and atmospheric sampling glow discharge ionization (ASGDI) has been used to perform chemical ionization using ambient gases. $^{12}$

Real-time mass spectrometry can detect low mass concentrations, but tandem mass spectrometry (MS/MS) is necessary for analyte chemical identification in mixture analysis. ${ }^{13-15}$ The TOFMS instruments most commonly used for aerosol detection are incapable of performing MS/MS. Quadrupole ion trap mass spectrometers can not only perform MS/MS but can
48 also readily perform multiple stages of MS/MS $\left(\mathrm{MS}^{\mathrm{n}}\right)$. Single

49 aerosol particles have been ionized in an ion trap with timed

50 UV laser shots as the particles passed through the center of the

51 trap. The ions created within the trap are then available for

52 MS $^{\text {n. }} .{ }^{16,17}$ This approach is limited to larger aerosol particles

53 that can be detected by laser scattering techniques to allow

54 appropriate timing of the UV laser shot. More recent methods

55 have used atmospheric pressure chemical ionization ${ }^{18,19}$ and

56 post-plasma ionization. ${ }^{20,21}$

57 The aerosol quadrupole ion trap mass spectrometer

58 (AQITMS) presented here characterizes any size aerosols in

59 real-time. The volatiliziation and ionization of aerosol com-

60 pounds is entirely internal to the instrument. An aerodynamic

61 lens $^{22,23}$ passes particles though a hole in one side of the ring

62 electrode into the trapping volume. The particles are volati-

63 lized upon impacting the opposite, inner surface of the heated

64 ring electrode. The vaporized particles are ionized within the

65 trapping electrodes by selected ion chemical ionization

66 (SICI). ${ }^{24}$ Subsequently any standard MS or MS/MS analysis

67 can be performed. As an example of the capabilities a mixture

68 of SOA products from $\alpha$-pinene ozonolysis carried out in an

69 aerosol bag are detected in real-time at ppb concentrations,

70 and analytes are identified with collision induced dissociation

71 (CID) MS/MS.

72

73 Methods

74 Instrumentation

75 A Finnigan ITD ${ }^{\mathrm{TM}}$ controlled with modified ITMS (Revi76 sion B) software was modified for detection of aerosol parti- 


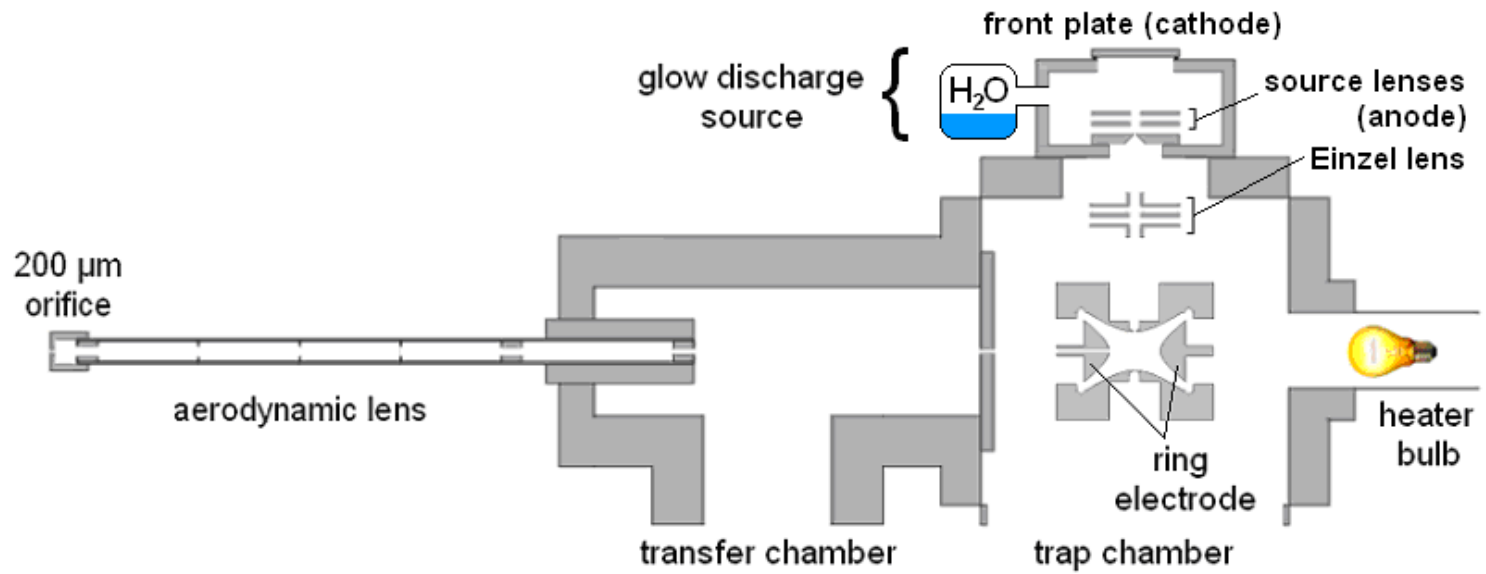

Figure 1. Schematic of AQITMS

cles. A schematic of the AQITMS apparatus is shown in Figure 1. The quadrupole ion trap has a $3.2 \mathrm{~mm}$ hole drilled through one side of the ring electrode for particles to enter the trapping volume. The high vacuum chamber containing

the trapping electrodes has a base pressure of $2.3 \times 10^{-5}$ Torr with the aerodynamic lens orifice open and $2 \times 10^{-7}$ Torr with the aerodynamic lens orifice closed, measured by an ion gauge on the chamber. Helium bath gas is added for a constant pressure of $1.0 \times 10^{-3}$ Torr for optimum sensitivity of the ion trap. A transfer chamber is separated from the ion trap chamber by a1.8 $\mathrm{mm}$ orifice and has a pressure of $80 \mathrm{mT}$ Torr. An aerodynamic lens is inserted in the transfer chamber opposite the orifice to the trap chamber. The ion trap chamber is pumped at $280 \mathrm{~L} / \mathrm{s}$ by the first stage of a Pfeiffer SplitFlow turbo pump, and the second stage pumps the transfer chamber at $205 \mathrm{~L} / \mathrm{s}$.

A Lesker $1000 \mathrm{~W}$ stab-in bakeout heater mounted under the ion trap electrodes heats the ring electrode surface to 50-130 ${ }^{\circ} \mathrm{C}$ to aid volatilization. The ring electrode surface temperature was calibrated against average helium bath gas temperature as measured by a k-type thermocouple in the trap chamber located $2 \mathrm{~cm}$ from the trapping electrodes. A second $\mathrm{k}$ type thermocouple on an (thermally conductive, electrically isolating) alumina surface in contact with the ring electrode was used to make the initial calibration. A temperature of 115 ${ }^{\circ} \mathrm{C}$ was used for volatilization unless otherwise noted.

The aerodynamic lens continuously samples air through a $200 \mu \mathrm{m}$ orifice at $0.3 \mathrm{~L} / \mathrm{m}$. Aerosol particles enter through the orifice, passing from atmospheric pressure to 5.1 Torr, as measured by a convection pressure gauge. Particles are focused by passing through the consecutive orifices within the aerodynamic lens and enter the transfer chamber. The particle beam passes into the trap chamber and then into the trapping region through the hole in the side of the ring electrode. Particles impact the opposite, inner surface of the heated ring electrode and volatilize. The diameter of the particle beam is visually inspected by collecting salt particles on a slide over the impact site. The salt particle spot has a diameter of approximately $1.5 \mathrm{~mm}$ after traveling a distance of $21.8 \mathrm{~cm}$ from the lens exit to impact within the ion trap.

For comparison of fragmentation patterns from single-component particles, mass spectra were also acquired with an aerosol time-of-flight mass spectrometer (ATOFMS) that has been described elsewhere. ${ }^{6,7}$ Single particles with great er than $100 \mathrm{~nm}$ diameter were volatilized with a $\mathrm{CO}_{2}$ laser and ionized with $118 \mathrm{~nm}$ vacuum UV photoionization.

\section{Aerosol Particle Generation and Size Measurement}

Standard single-compound and mixture solutions of organic acids (Sigma Chemical, St. Louis, MO) were made to between $40 \mu \mathrm{M}$ to $1.5 \mathrm{mM}$ in water. Aerosol particles were generated from the solutions with a constant output atomizer (TSI 3076, Shoreview, MN). Particles were sampled directly with coductive tubing from the particle source to the aerodynamic lens orifice.

Secondary organic aerosol (SOA) particles were generated by ozonolysis of $\alpha$-pinene in a $500 \mathrm{~L}$ Teflon bag. The bag was initially passivated with ozone. The absence of background aerosols was confirmed using a TSI scanning mobility particle sizer (SMPS) consisting of a 3081 dynamic mobility analyzer and a 3022a condensation particle counter. The bag was then filled with air at $22{ }^{\circ} \mathrm{C}$ and $16.75 \%$ relative humidity passed through a MKS 647B mass flow controller. Ozone was generated by passing medical-grade air through an ozone generator (model L11, Pacific Ozone Technology, Benicia, CA). The ozone was diluted by a factor of 45 with air before its concentration was determined by a $10 \mathrm{~cm}$ long home-built absorption cell monitoring light absorption at $\lambda=254 \mathrm{~nm} .{ }^{25}$ The diluted oxygen was then flowed into the bag to a concentration $200 \mathrm{ppb}$ in air. A liquid sample of $\alpha$-pinene evaporated immediately upon injection directly into the closed bag and was allowed to mix for 1-2 minutes. After mixing, the valve on the bag was opened to conductive tubing to the aerodynamic lens for continuous, direct sampling. Following the conclusion of an experiment, the bag was evacuated and purged with air, which was analyzed to ensure that no reaction products remained.

The SMPS was used to measure the mass concentration of particles. Particles with diameters between 14.9 and $673 \mathrm{~nm}$ were counted. Depending on the compound and its concentration in solution, the mean diameter of the particles formed was between 40 and $100 \mathrm{~nm}$. Aerosol sample lines were split to the SMPS and to the aerodynamic lens orifice on the AQITMS for simultaneous measurement of particle mass concentration and acquisition of mass spectra. Ninety mass spectra were averaged during the $135 \mathrm{~s}$ for a SMPS mass measurement. Some 103 particles are sampled by the AQITMS per second, as measured by the SMPS. Given the reduced transmission efficiency for ultrafine particles with 

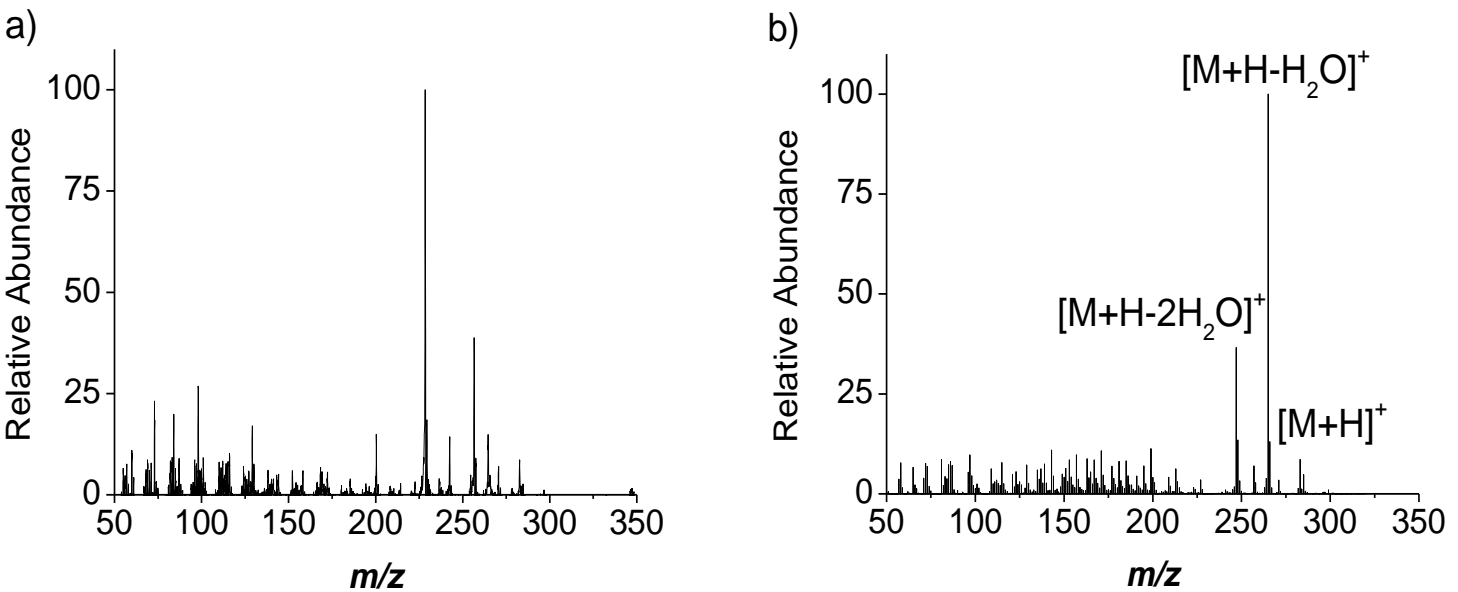

Figure 2. a) Vacuum UV photoionization of volatilized oleic acid particles in the extraction region of ATOFMS, and b) proton transfer SICI of volatilized oleic acid particles in the trapping volume of the AQITMS.

\section{transfer SICI of volatilized oleic acid particles in the trapping vo}

the aerodynamic lens, the actual number of particles contributing to AQITMS signal is significantly smaller. ${ }^{2}$

\section{Glow Discharge Ionization Source and SICI}

$\mathrm{H}_{3} \mathrm{O}^{+}$reagent ions are generated by glow discharge ionization (GDI) of water vapor in a source region on the trap chamber orthogonal to the transfer chamber and aerodynamic lens (see Figure 1). The source has a base air pressure of 0.05 Torrmeasured by a capacitance manometer, and water vapor is leaked in to a pressure of 0.14 Torr. A high voltage of -850 to $-950 \mathrm{~V}$ is applied to the front plate cathode to induce a 2.2 $\mathrm{mA}$ glow discharge between the front plate and an anode at $30 \mathrm{~V} . \mathrm{H}_{3} \mathrm{O}^{+}$reagent ions from the glow discharge are gated into the ion trap by an Einzel lens for $500 \mathrm{~ms}$. Aerosol particles are continuously supplied to the trap in bulk for volatilization and SICI. For SICI all ions injected into the ion trap from the GDI source except $\mathrm{H}_{3} \mathrm{O}^{+}$are ejected using standard ion trap techniques. The $\mathrm{H}_{3} \mathrm{O}^{+}$ions transfer protons to the higher proton affinity analyte molecules. Another $500 \mathrm{~ms}$ period is allotted for SICI before analyte ions are ejected for detection. $\mathrm{H}_{3} \mathrm{O}^{+}$reagent ions are also generated within the trap for SICI. Some electrons overcome the Einzel lens barrier to enter the trapping volume and ionize molecules from the residual air in the trap. Analyte compounds are far less abundant than ambient air molecules coming in through the aerodynamic lens so there is negligible electron ionization of analyte compounds. However, $\mathrm{N}_{2}^{+\bullet}$ rapidly charge exchanges with water molecules, and the $\mathrm{H}_{2} \mathrm{O}^{+\bullet}$ reacts to form more hydronium ions in the trap. The gate and reaction times and the number of scans averaged were adjusted depending on the speed and sensitivity required in experiments. $\mathrm{N}_{2}{ }^{+\bullet}$ also charge exchanges with oxygen forming $\mathrm{O}_{2}^{+\bullet}$ reagent ions. A combined gate and reaction time of more than $100 \mathrm{~ms}$ gave enough signal from $\mathrm{H}_{3} \mathrm{O}^{+}$reagent ions and $\mathrm{O}_{2}^{+} \bullet$ reagent ions to saturate the detector (not shown). Unit mass resolution was achieved for analyte ions above $\mathrm{m} / z, 50$ despite space charge effects from such excess ion populations.

Collision induced dissociation of analyte ions was performed by applying resonant waveform voltages to the endcap trapping electrodes. Stored waveform inverse Fouri er transform (SWIFT) was implemented with LabVIEW to construct the waveforms. ${ }^{26}$ A 1.0-2.8 $\mathrm{V}_{\mathrm{p}-\mathrm{p}}$ SWIFT waveform from an arbitrary waveform generator was applied to dissociate a parent ion at a $\mathrm{q}_{\mathrm{z}}$ of 0.25 for CID.

\section{Results and Discussion}

\section{Selected Ion Chemical Ionization}

Sensitivity is improved by reducing fragmentation of the protonated molecule or molecular ion. Proton transfer SICI with the AQITMS caused less fragmentation than vacuum UV photoionization, a technique in aerosol particle mass spectrometry designed specifically to reduce fragmentation of organic compounds. ${ }^{27} \mathrm{~A}$ mass spectrum acquired from vacuum UV photoionization of volatilized oleic acid particles in the extraction region of the ATOFMS is shown in Figure 2a. The molecular ion comprises less than $1 \%$ of total ion signal. The most intense peak in the spectrum comprised $10.6 \%$ of total ion signal and was formed along with many other peaks above and below $\mathrm{m} / \mathrm{z}, 200$ due to aliphatic fragmentation. The number of peaks makes assignment difficult and would greatly complicate spectra from a mixture of compounds. In contrast, a mass spectrum acquired from SICI of volatilized oleic acid particles in the trapping volume of the AQITMS is shown in Figure $2 \mathrm{~b}$. The protonated molecule $[\mathrm{M}+\mathrm{H}]^{+}$comprised $1.5 \%$ total ion signal, but the peaks below $\mathrm{m} / \mathrm{z} 200$ have smaller abundance than in the vacuum UV mass spectrum. Unlike photoionization, the majority of the signal comes from just two peaks due to water losses from the protonated molecule, $\left[\mathrm{M}+\mathrm{H}-\mathrm{H}_{2} \mathrm{O}\right]^{+}$and $\left[\mathrm{M}+\mathrm{H}-2 \mathrm{H}_{2} \mathrm{O}\right]^{+}$. Sensitivity was increased with SICI because the most intense peak is increased to $16.7 \%$ of total ion current. Use of other CI reagent ions could substantially reduce the amount of fragmentation observed in this spectrum.

The temperature of the ring electrode surface and bath gas directly affected ion fragmentation and sensitivity of SICI mass spectra. Heating the ring electrode was necessary for efficient volatilization of aerosol particles with low vapor pressure (oleic acid $1.69 \times 10^{-5} \mathrm{~Pa}$ ). As the temperature was decreased, particles adsorbed to the ring electrode surface and required increasing time to desorb (Figure 3a). A ring electrode temperature of at least $105{ }^{\circ} \mathrm{C}$ was necessary for 
a)

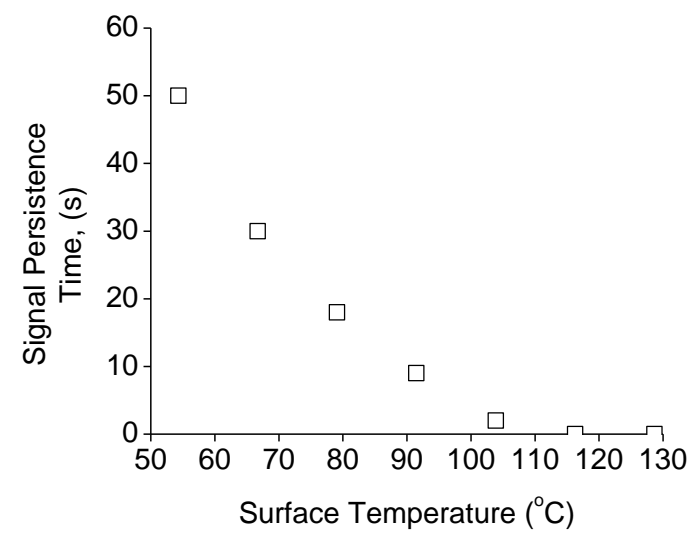

b)

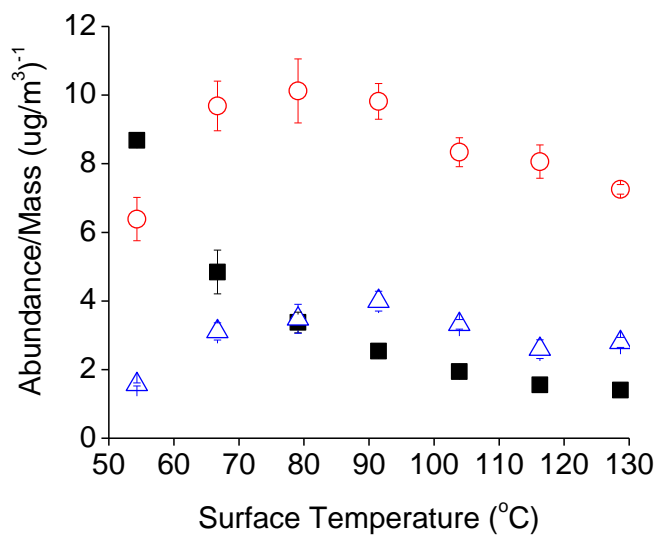

6 complete instantaneous volatilization of particles at 100-200

$7 \mu \mathrm{g} / \mathrm{m}^{3}$ for SICI. Higher minimum surface temperature was

8 required for increasing particle mass concentration. Con-

9 versely, the observed abundance of $\mathrm{H}_{3} \mathrm{O}^{+}$reagent ions after

10 the same gate time decreased with increasing temperature in

11 the ion trap chamber. Lower bath gas temperatures caused

12 less fragmentation of $[\mathrm{M}+\mathrm{H}]^{+}$ions (Figure $3 \mathrm{~b}$ ), and back-

13 ground also decreased with decreasing temperature. To bal-

14 ance the effects, the minimum surface temperature is used for

15 volatilization without signal persistence. Signal response was

16 linear with particle mass concentration at a given volatiliza-

17 tion temperature. Oleic acid particles at mass concentrations

18 from $10-1100 \mu \mathrm{g} / \mathrm{m}^{3}$ were volatilized at $115^{\circ} \mathrm{C}$ for linear sig-

19 nal response with $\mathrm{R}^{2}=0.995$ (Supporting Information Figure

20 S-1). The volatilization temperature could also be reduced for

21 more sensitive detection of lower particle concentrations. The

22 limit of detection $\left(\mathrm{S} / \mathrm{N} \geq 3\right.$ ) was $5 \mu \mathrm{g} / \mathrm{m}^{3}$ for oleic acid volati-

23 lized at $80{ }^{\circ} \mathrm{C}$, equal to other $\mathrm{CI}$ aerosol detection schemes. ${ }^{10}$

\section{Characterization of Aerosol Particle Standards}

Homogeneous pinic acid or pinonic acid aerosol particles were analyzed with the AQITMS. A typical mass spectrum

a)

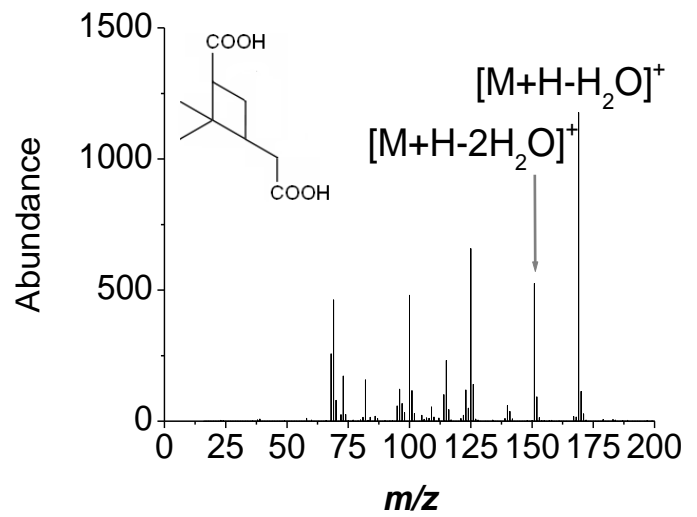

28 for pinic acid is shown in Figure 4a. The most abundant prod29 uct ion in the mass spectrum is $\left[\mathrm{M}+\mathrm{H}-\mathrm{H}_{2} \mathrm{O}\right]^{+}$at $\mathrm{m} / \mathrm{z} 169$, and 30 a significant abundance of $\left[\mathrm{M}+\mathrm{H}-2 \mathrm{H}_{2} \mathrm{O}\right]^{+}$was also observed. 31 Several other fragment ions were also observed. The pinonic 32 acid mass spectrum also has water-loss fragment ions, at $m / z$ 33167 and 149 , but other fragment ions were more abundant 34 (Figure 4b). The structural similarity of the molecules pro35 duced two identical fragment ions at $\mathrm{m} / \mathrm{z}, 125$ and 115 , which 36 cannot be used to characterize the two compounds in a mix37 ture.

38 AQITMS signal was compared against particle mass con39 centration as measured by the SMPS to make calibration 40 curves. Mass spectra of pinic acid particles at concentrations 41 up to $170 \mu \mathrm{g} / \mathrm{m}^{3}$ were observed with linear signal response at $42 \mathrm{R} 2=0.998$, and the limit of detection $(\mathrm{S} / \mathrm{N} \geq 3)$ of $43\left[\mathrm{M}+\mathrm{H}-\mathrm{H}_{2} \mathrm{O}\right]^{+}$was $20 \mu \mathrm{g} / \mathrm{m}^{3}$. The mass concentration of pi44 nonic acid could not be accurately measured with the SMPS 45 at the same residence time, and a calibration curve could not 46 be made. Although both compounds are generally classified 47 as low volatility, the thirty times higher calculated vapor pres48 sure of pinonic acid $\left(1.84 \times 10^{-2} \mathrm{~Pa}\right)$ compared to pinic

b)

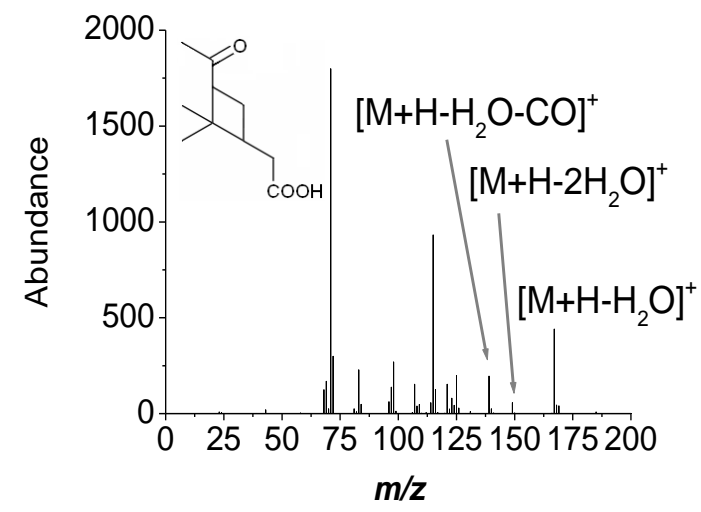


1 acid $\left(5.87 \times 10^{-4} \mathrm{~Pa}\right)$ may cause significant underestimation of 2 particle mass compared to pinic acid through evaporative 3 losses in sampling lines.

\section{Multi-component Aerosol Particles}

Multi-component particles were generated from different solution mixtures of pinic acid and pinonic acid. Ninety mass spectra were acquired at each of three different particle mass concentrations for five mole ratios of pinic acid to pinonic acid. Fragment ions from each compound were identified based on mass spectra of single-component particles. For each set of averaged AQITMS spectra, the intensities of the five most abundant fragment ions for each component compound were summed to find the total signal for pinic acid and pinonic acid, respectively. Finally, the ratio of pinic acid signal to pinonic acid signal was plotted against the mole ratio of the compounds in solution. The resultant linear calibration curve had a slope of 0.5519 and $\mathrm{R}^{2}=0.996$. The plot does not have a slope of one because not every ion signal for each analyte was included in the total. Fragment ions $\mathrm{m} / \mathrm{z}, 125$ and 115 cannot be assigned when both compounds are present, and low-abundance fragment ions might not be observed over noise at low particle mass concentrations. Using the same mass spectra, the ratio of pinic acid signal to pinonic acid signal was also computed from the abundance of the largest observed ion for each compound, $\left[\mathrm{M}+\mathrm{H}-\mathrm{H}_{2} \mathrm{O}\right]^{+}$. The single ion linear calibration curve of AQITMS signal ratio against mole ratio of the compounds in solution had a slope of 1.6046 and $\mathrm{R}^{2}=0.995$. The greater slope reflects the reduced fragmentation of pinic acid $\left[\mathrm{M}+\mathrm{H}-\mathrm{H}_{2} \mathrm{O}\right]^{+}$compared to pinonic acid. The linearity of the mole ratio calibration curves verifies that all compounds in mixture particles are volatilized with equal efficiency, despite the difference in vapor pressure of the composite compounds.

Unlike the signal response from the AQITMS, total mass concentration measurements with the SMPS did not have a linear relationship to the ratio of components in particles. The different vapor pressures of pinic acid and pinonic acid caused nonlinear response with increasing amounts of pinonic acid. a)

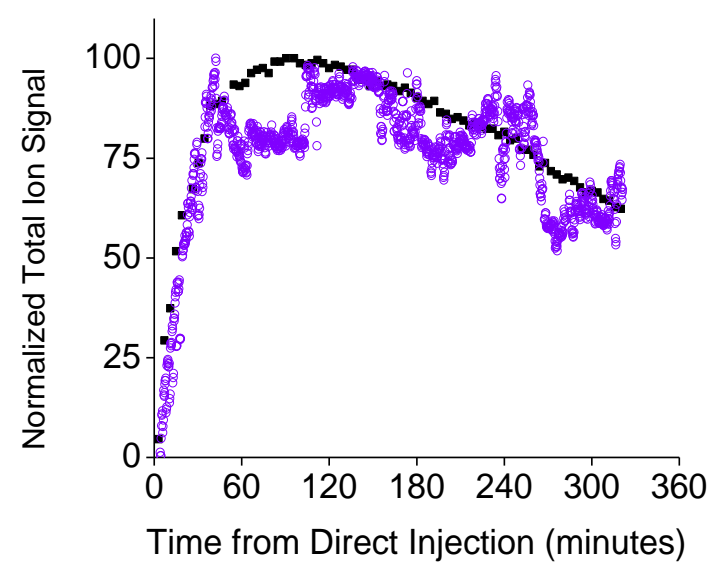

Empirical corrections could be made for a simple mixture of two known components to compensate for evaporative losses. However, the complexity of a bulk sample containing multiple different, possibly unknown components with different vapor pressures suggests that accurate results from SMPS measurements would require extensive empirical study. A single component compound with low vapor pressure is used as an internal standard to measure the concentration of other compounds. The pinic acid single-component calibration curve against the SMPS gives mass concentration based on AQITMS signal, and the mole ratio to another analyte (in this case pinonic acid) is given by the observed AQITMS ion signal ratio. Comparing the signal ratios between one fragment ion per analyte reduces the likelihood of another compound contributing an isobaric ion. Using MS/MS product ions would further reduce the likelihood of interference, but at a sensitivity cost.

\section{Secondary Organic Aerosol Detection}

Secondary organic aerosol particles from ozonolysis of $\alpha$ pinene were sampled from an aerosol bag for real-time detection with the AQITMS. The bag contained $200 \mathrm{ppb}$ ozone in air, and the $0.3 \mu \mathrm{L}$ sample of $\alpha$-pinene injected into the bag yielded a volumetric concentration of $100 \mathrm{ppb}$. SOA particles were detected in the first spectrum acquired after the bag was opened to the sampling orifice. Particles were observed continuously over the next 5.5 hours until sampling was ended. Thirty scans of the AQITMS were averaged during every 38 s period after sampling began. AQITMS particle signal grew steadily for the first 42 minutes during particle nucleation and growth (Figure 5a). ${ }^{28}$ Total particle signal and mass concentration fluctuated compared to SMPS measurements throughout the remaining sample time as different SOA compounds were formed at different rates and may have undergone tertiary reactions. Overall signal gradually decayed as particles were lost to the walls of the bag. Pinic acid and pinonic acid fragment ions were observed

b)

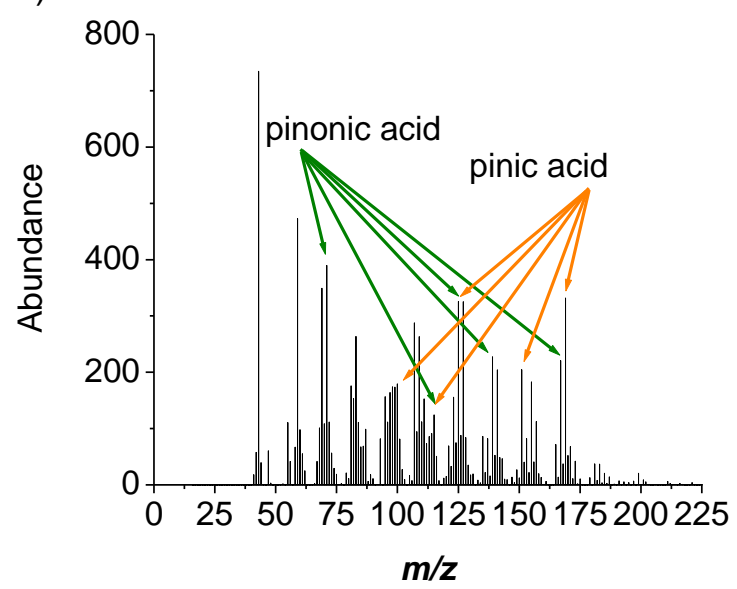


a)

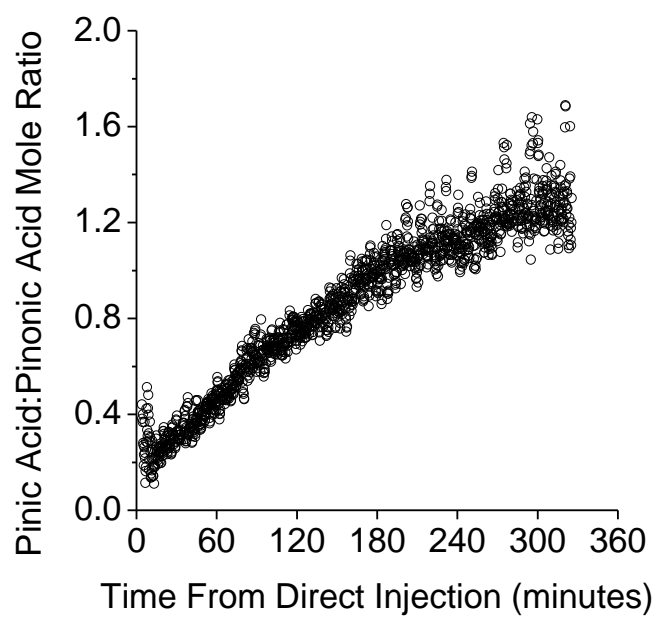

b)

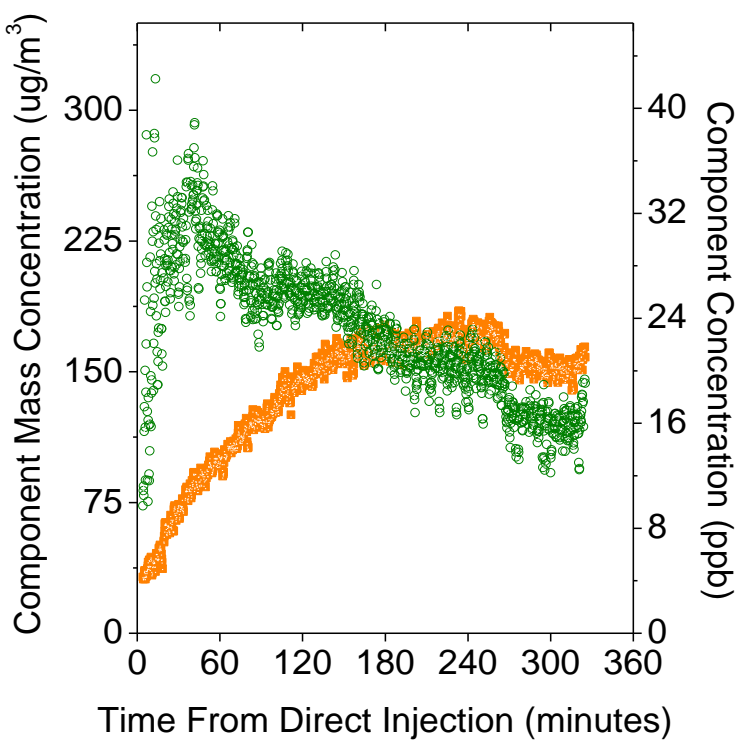

Figure 6. As a function of time from after direct injection of $\alpha$-pinene into aerosol bag, a) mole ratio of pinic acid to pinonic acid in SOA particles, and b) mass concentration in particles $\left(\mu \mathrm{g} / \mathrm{m}^{3}\right)$ and concentration in aerosol bag (ppb) of pinic acid ( $\square$ ) and pinonic $\operatorname{acid}(\circ)$.

6 along with ions from other SOA compounds throughout the 40

7 sample time, and a typical spectrum is shown in Figure 5b. The 41

8 relative intensities of some fragment ion signals associated with 42

9 either acid did not have the same proportion to $\left[\mathrm{M}+\mathrm{H}-\mathrm{H}^{2} \mathrm{O}\right]^{+} 43$

10 ions as in the spectra of single-component particles. Other ozo- 44

11 nolysis reaction products with similar structure ${ }^{29-31}$ that have not 45

12 been characterized with the AQITMS likely form the isobaric 46 or isomeric ions.

The changing concentrations of SOA particle components 48 throughout the analysis were calculated from AQITMS spectra. 49
The ratio between pinic acid and pinonic acid $\left[\mathrm{M}+\mathrm{H}-\mathrm{H}_{2} \mathrm{O}\right]^{+}$ion 50 signals in each spectrum was used to calculate the actual mole 51 ratio of the compounds in the multi-component SOA particles 52 using the previous mole ratio calibration curve (Figure 6a). The 53 observed mole ratio fell within the limits of the calibration 54 curve. The real-time concentration in the bag and partial mass 55 concentration in particles was calculated for pinic acid from the 56 abundance of pinic acid $\left[\mathrm{M}+\mathrm{H}-\mathrm{H}_{2} \mathrm{O}\right]^{+}$ions and the single-com- 57 ponent particle SMPS calibration curve (Figure 6b). Pinonic 58 acid increased by four times to peak at $36 \mathrm{ppb}$ at the same time 59 as overall ion signal, and pinic acid increased by six times over 60 four hours to $24 \mathrm{ppb}$. The combined mass concentration of 61 pinic acid and pinonic acid varied directly with the total particle 62 signal throughout sampling time (Supporting Information Fig- 63 ure S-2), although other SOA compounds contributed the ma- 64 jority of the signal.

\section{Tandem Mass Spectrometry}

Tandem mass spectrometry identifies compounds in aerosols 69 by the product ions unique to different compounds. CID of the oleic acid formed many product ions. The most abundant prod- 70 uct ion from CID of oleic acid parent ion $\left[\mathrm{M}+\mathrm{H}-\mathrm{H}_{2} \mathrm{O}\right]^{+}$came 71 from a second water loss (Supporting Information Figure S-3). 72 CID of either water loss ion produced three ion series from the 73 double bond in oleic acid and double bonds formed after dehydration. Pinic acid and pinonic acid gave fewer product ions. CID of $\left[\mathrm{M}+\mathrm{H}-\mathrm{H}_{2} \mathrm{O}\right]^{+}$ions usually resulted (additional) water loss and $\mathrm{CO}$ loss from oxygenated functional groups. $\mathrm{MS}^{\mathrm{n}}$ of pinic acid $\left[\mathrm{M}+\mathrm{H}-\mathrm{H}_{2} \mathrm{O}\right]^{+}$was necessary to form enough different product ions to identify the compound.

Ions from SOA particles were identified as they were formed in real-time. The respective $\left[\mathrm{M}+\mathrm{H}-\mathrm{H}_{2} \mathrm{O}\right]^{+}$ions were used to identify pinic acid and pinonic acid despite not being the most abundant pinonic acid fragment ion observed from single component particles. Smaller mass-to-charge fragment ions may be identical to fragment ions from uncharacterized SOA compounds with similar structures and would not be differentiated by CID. The $\left[\mathrm{M}+\mathrm{H}-\mathrm{H}_{2} \mathrm{O}\right]^{+}$at $\mathrm{m} / \mathrm{z} 169$ from pinic acid can be formed by dehydration of either of two carboxylic acids, and CID of this ion produced a second water loss (Supporting Information Figure S-4). More informative product ions are required to distinguish pinic acid in the SOA mixture. $\mathrm{MS}^{\mathrm{n}}$ dissociation of $\left[\mathrm{M}+\mathrm{H}-2 \mathrm{H}_{2} \mathrm{O}\right]^{+}$produced losses of $\mathrm{CO}$ and $\mathrm{CH}_{2} \mathrm{CO}$. The $\left[\mathrm{M}+\mathrm{H}-\mathrm{H}_{2} \mathrm{O}\right]^{+}$from pinonic acid is formed by dehydration of the single carboxylic acid, and dissociation of $\mathrm{m} / \mathrm{z} 167$ produced a second water loss from the ketone and/or loss of either remaining $\mathrm{CH}_{2} \mathrm{CO}$ group (Supporting Information Figure S-5). The unique CID product ions for both compounds matched the reference spectra of each. The real-time identification of $\left[\mathrm{M}+\mathrm{H}-\mathrm{H}_{2} \mathrm{O}\right]^{+}$ions from pinic acid and pinonic acid as the only ions at their respective mass-to-charge values confirms the observed AQITMS signals as the basis for concentration calculations.

\section{Conclusions}

The AQITMS performs aerosol particle detection and analysis using a sensitive, efficient, and $\mathrm{MS}^{\mathrm{n}}$-capable instrumental design. Particles are delivered to the heated trapping volume via an aerodynamic lens and volatilized. Proton transfer SICI 


\section{ASSOCIATED CONTENT}

\section{AUTHOR INFORMATION}

\section{Corresponding Author}

$27 *$ Department of Chemistry

28 University of North Carolina at Chapel Hill

29 Chapel Hill, NC 27599-3290

\section{Author Contributions}

All authors have given approval to the final version of the manuscript.

\section{ACKNOWLEDGMENT}

This work was supported by NSF grant \# ATM-0711097. Thanks 92 to the University of North Carolina-Chapel Hill Chemistry Dept. 93 machine shop for producing several vacuum components, and to 94 Dr. Tomas Baer for supplying the aerodynamic lens.

\section{Supporting Information Available}

This information is available free of charge via the Internet at 99 http://pubs.acs.org/.

\section{REFERENCES}

1. Sullivan, R. C.; Prather, K. A. Analytical Chemistry 2005, 77103 3861-3886.

2. Nash, D. G.; Baer, T.; Johnston, M. V. International Journal of 05 Mass Spectrometry 2006, 258, 2-12.

3. McKeown, P. J.; Johnston, M. V.; Murphy, D. M. Analytical 07 Chemistry 1991, 63, 2069-2073.

4. Mansoori, B.; Johnston, M.; Wexler, A. Analytical Chemistry 1994, 66, 3681-3687.
5. Sykes, D. C.; Ephraim Woods, I.; Smith, G. D.; Baer, T.; Miller, R. E. Analytical Chemistry 2002, 74, 2048-2052.

6. Woods, E., III; Smith, G. D.; Dessiaterik, Y.; Baer, T.; Miller, R. E. Analytical Chemistry 2001, 73, 2317-2322.

7. Rosen, E. P.; Garland, E. R.; Baer, T. Journal of Physical Chemistry A 2008, 112, 10315-10324.

8. Voisin, D.; Smith, J. N.; Sakurai, H.; McMurry, P. H.; Eisele, F. L. Aerosol Science and Technology 2003, 37, 471-475.

9. Tobias, H. J.; Ziemann, P. J. Analytical Chemistry 1999, 71, 34283435.

10. Hearn, J. D.; Smith, G. D. Analytical Chemistry 2004, 76, 28202826.

11. Kercher, J. P.; Riedel, T. P.; Thornton, J. A. Atmospheric Measurement Techniques 2009, 2, 193-204.

12. Dalton, C. N.; Jaoui, M.; Kamens, R. M.; Glish, G. L. Analytical Chemistry 2005, 77, 3156-3163.

13. McLafferty, F. W. Tandem Mass Spectrometry; John Wiley and Sons: New York, 1983.

14. Busch, K. L.; Glish, G. L.; McLuckey, S. A. Mass Spectrometry/ Mass Spectrometry: Techniques and Applications of Tandem Mass Spectrometry; VCH: New York, 1988.

15. Glish, G. L.; Vachet, R. W. Nature Reviews Drug Discovery 2003, $2,140-150$.

16. Dale, J. M.; Yang, M.; Whitten, W. B.; Ramsey, J. M. Analytical Chemistry 1994, 66, 3431-3435.

17. Reilly, P. T. A.; Gieray, R. A.; Yang, M.; Whitten, W. B.; Ramsey, J. M. Analytical Chemistry 1997, 69, 36-39.

18. Held, A.; Rathbone, G. J.; Smith, J. N. Aerosol Science and Technology 2009, 43 (3), 264-272.

19. Vogel, A. L.; Aijala, M.; Brueggemann, M.; Ehn, M.; Junninen, H.; Petaja, T.; Worsnop, D. R.; Kulmala, M.; Williams, J.; Hoffmann, T. Atmospheric Measurement Techniques 2013, 6 (2), 431 443.

20. Spencer, S. E.; Tyler, C. A.; Tolocka, M. P.; Glish, G. L. Analytical Chemistry 2015, 87 (4), 2249-2254.

21. Brueggemann, M.; Karu, E.; Stelzer, T.; Hoffmann, T. Environmental Science \& Technology 2015, 49 (9), 5571-5578.

22. Liu, P.; Ziemann, P. J.; Kittelson, D. B.; McMurry, P. H. Aerosol Science and Technology 1995, 22, 293-311.

23. Liu, P.; Ziemann, P. J.; Kittelson, D. B.; McMurry, P. H. Aerosol Science and Technology 1995, 22, 314-324.

24. Glish, G. L.; VanBerkel, G. J.; Asano, K. G.; McLuckey, S. A., San Francisco, CA 1988; 1112-1113.

25. Smith, G. D.; Ephraim Woods, I.; DeForest, C. L.; Baer, T.; Miller, R. E. Journal of Physical Chemistry A 2002, 106, 8085-8095.

26. Asam, M. R.; Ray, K. L.; Glish, G. L. Analytical Chemistry 1998 , 70, 1831-1837.

27. Tolocka, M. P.; K.J. Heaton; Dreyfus, M. A.; Wang, S.; Zordan, C. A.; Saul, T. D.; Johnston, M. V. Envionmental Science and Technology 2006, 40, 1843-1848.

28. Lee, S.; Kamens, R. M. Atmospheric Environment 2005, 39, 6822-6832.

29. Calogirou, A.; Larsen, B. R.; Kotzias, D. Atomospheric Environment 1999, 33, 1423-1439.

30. Kamens, R.; Jang, M.; Chien, C.-J.; Leach, K. Envionmental Science and Technology 1999, 33, 1430-1438.

31. Jang, M.; Kamens, R. M. Atmospheric Environment 1999, 33, 459-474. 


\section{Figure Captions}

Figure 1. Schematic of AQITMS.

Figure 2. a) Vacuum UV photoionization of volatilized oleic acid particles in the extraction region of ATOFMS, and b) proton transfer SICI of volatilized oleic acid particles in the trapping volume of the AQITMS.

Figure 3. SICI of oleic acid particles at $100-200 \mu \mathrm{g} / \mathrm{m}^{3}$ at different temperatures of the ring electrode surface: a) time for signal to decay to baseline after particle source is removed, and b) analyte ion abundance normalized by particle mass concentration for $[\mathrm{M}+\mathrm{H}]^{+}(\mathbf{\square}),\left[\mathrm{M}+\mathrm{H}_{-}-\mathrm{H}_{2} \mathrm{O}\right]^{+}(\mathrm{O})$, and $\left[\mathrm{M}+\mathrm{H}-2 \mathrm{H}_{2} \mathrm{O}\right]^{+}$ $(\Delta),(95 \%$ confidence error bars $)$.

Figure 4. AQITMS mass spectra of a) pinic acid and b) pinonic acid.

Figure 5. SOA particles from reaction of $200 \mathrm{ppb}$ ozone with $100 \mathrm{ppb} \alpha$-pinene in air, a) normalized AQITMS total ion signal ( $($ ) and normalized SMPS total particle mass concentration ( $\square$ ) throughout sampling time, and b) 100 minutes after direct injection of $\alpha$-pinene into aerosol bag.

Figure 6. As a function of time from after direct injection of $\alpha$-pinene into aerosol bag, a) mole ratio of pinic acid to pinonic acid in SOA particles, and b) mass concentration in particles $\left(\mu \mathrm{g} / \mathrm{m}^{3}\right)$ and concentration in aerosol bag (ppb) of pinic acid ( $\square$ ) and pinonic acid ( $\odot$ ). 
2

For TOC Only

Glow discharge source

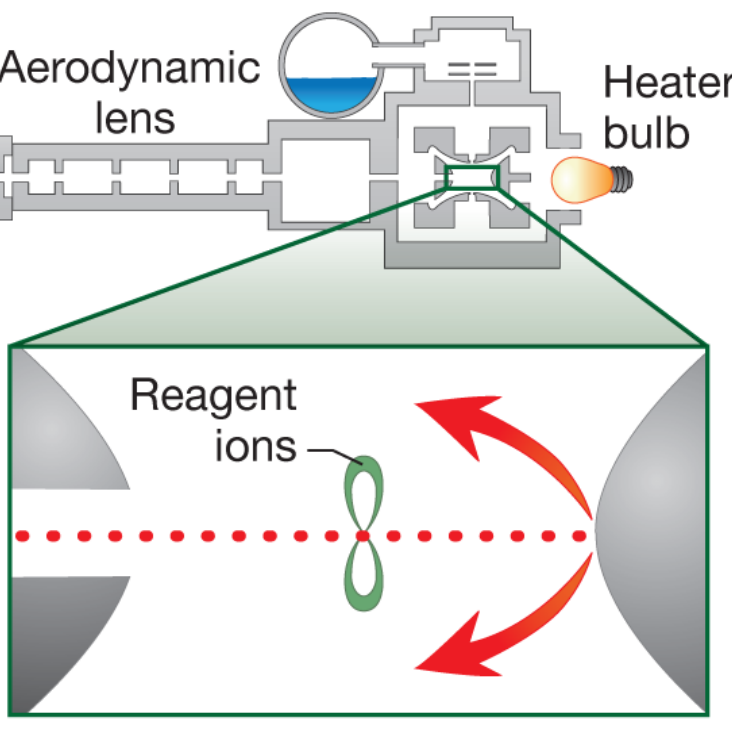

4 


\title{
Real-time Detection and Tandem Mass Spectrometry of Secondary Organic Aerosols with a Quadrupole Ion Trap
}

Supporting Information

\author{
G. Asher Newsome ${ }^{\mathrm{a}}$, Elias P. Rosen ${ }^{\mathrm{a}, \mathrm{b}}$, Richard M. Kamens ${ }^{\mathrm{b}}$, Gary L. Glish ${ }^{\mathrm{a} *}$ \\ ${ }^{a}$ Department of Chemistry, University of North Carolina at Chapel Hill, Chapel Hill, NC 27599-3290 \\ ${ }^{b}$ Department of Environmental Sciences and Engineering, University of North Carolina at Chapel Hill, Chapel Hill, \\ NC 27599-3290
}

The below supporting information contains Figure S-1, which is sourced from the same mass spectra as Figure 2a. The supporting figure demonstrates relationships between the deprotonated molecule $[\mathrm{M}-\mathrm{H}]^{+}$and its ammonia adduct $\left[\mathrm{M}-\mathrm{H}+\mathrm{NH}_{3}\right]^{+}$, as well as with the protonated molecule and its fragment ions. Although a change in the ratio between the deprotonated ion adducts is noted with change in humidity, there is no significant change in the ratio between the sum of protonated molecule adduct ions and the sum of deprotonated molecule adduct ions. The affinity of molecular adduct ions for protons or ammonia is not changed by humidity, and the respective mechanisms are not competitive. The data is included for completeness because of the high relative abundance of $[\mathrm{M}-\mathrm{H}]^{+}$and $\left[\mathrm{M}-\mathrm{H}+\mathrm{NH}_{3}\right]^{+}$compared to other ions in the mass spectra. 


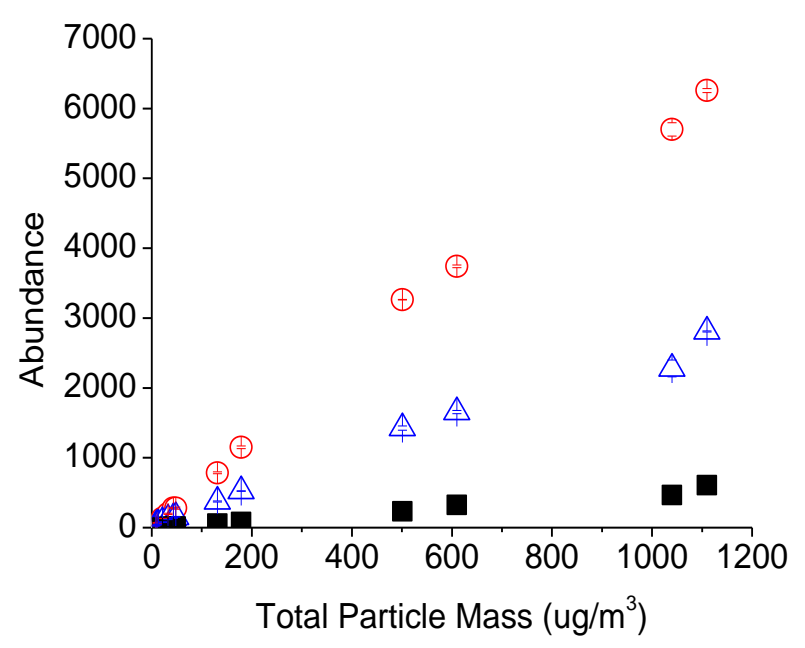

Supporting Information Figure S-1. AQITMS signal abundance from oleic acid particles volatilized at $115^{\circ} \mathrm{C}$ for $[\mathrm{M}+\mathrm{H}]^{+}(\mathbf{\square}),\left[\mathrm{M}+\mathrm{H}-\mathrm{H}_{2} \mathrm{O}\right]^{+}(\mathrm{O})$, and $\left[\mathrm{M}+\mathrm{H}-2 \mathrm{H}_{2} \mathrm{O}\right]^{+}(\Delta),(95 \%$ confidence error bars). 


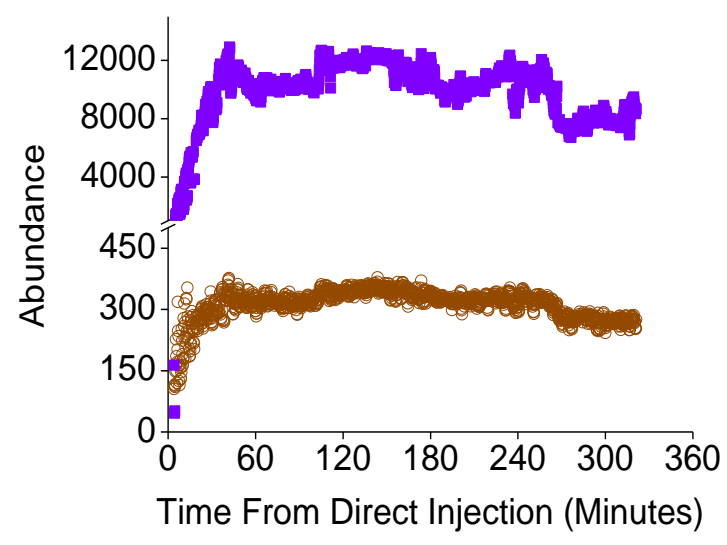

Supporting Information Figure S-2. The total AQITMS particle signal counts ( $\square$ ) and the combined calibrated mass measurements of pinic acid and pinonic acid in $\mu \mathrm{g} / \mathrm{m}^{3}(\circ)$ as a function of time from direct injection of $\alpha$-pinene into aerosol bag. 


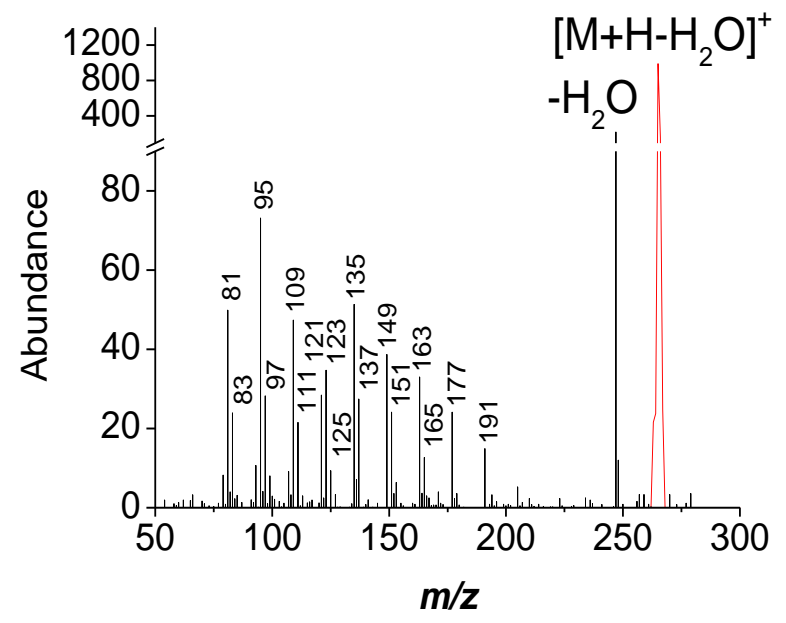

Supporting Information Figure S-3. CID of oleic acid $\left[\mathrm{M}+\mathrm{H}-\mathrm{H}_{2} \mathrm{O}\right]^{+}$(red trace). Product ions are labeled by mass-to-charge. 


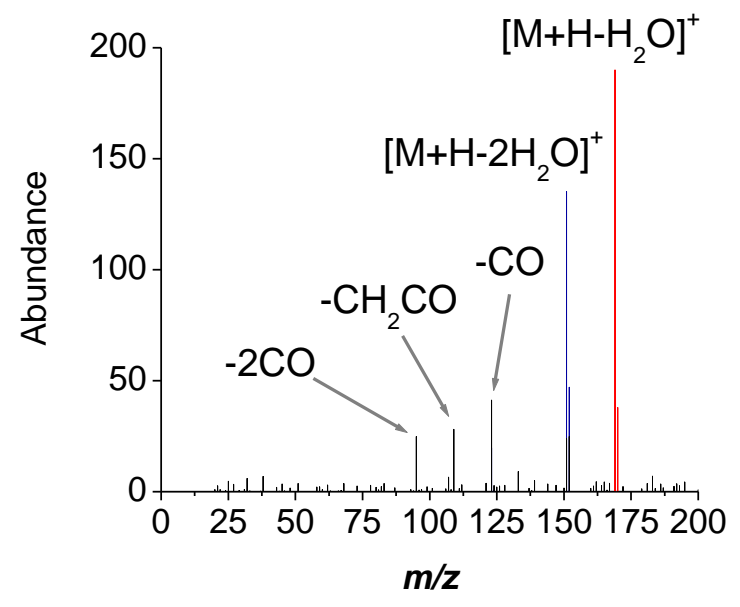

Supporting Information Figure S-4. CID of pinic acid fragment ions $\left[\mathrm{M}+\mathrm{H}-\mathrm{H}_{2} \mathrm{O}\right]^{+}$(red trace) and $\left[\mathrm{M}+\mathrm{H}-2 \mathrm{H}_{2} \mathrm{O}\right]^{+}$(blue trace) observed from $\alpha$-pinene ozonolysis at 70 minutes after direct injection. Product ions are denoted by mass lost from smallest mass-to-charge ion in colored trace. 


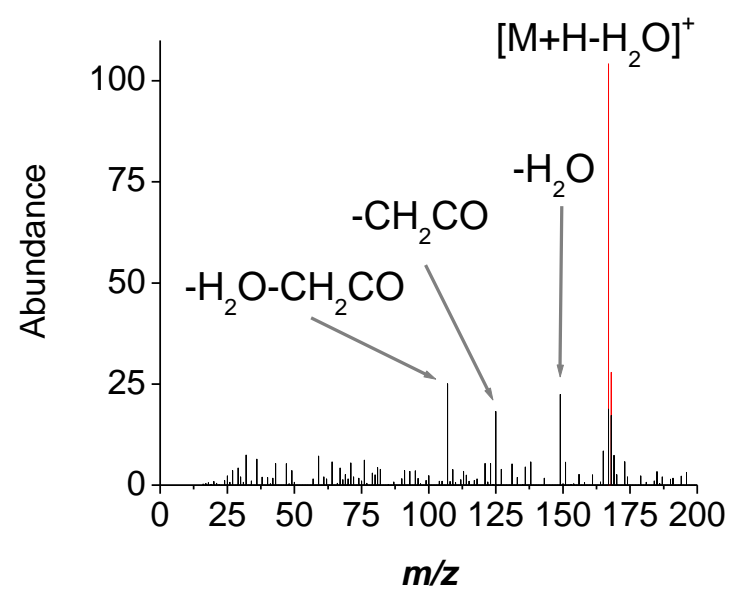

Supporting Information Figure S-5. CID of pinonic acid fragment ion $\left[\mathrm{M}+\mathrm{H}_{-}-\mathrm{H}_{2} \mathrm{O}\right]^{+}$(red trace) at 50 minutes after direct injection. Product ions are denoted by mass lost from smallest mass-tocharge ion in colored trace. 